\title{
Influence of autoinoculum on basic oenological parameters of wine
}

\author{
Radim Holesinsky ${ }^{1}$, Bozena Prusova ${ }^{1 *}$, Mojmir Baron ${ }^{1}$, Jaromir Fiala $^{2}$, Eliska Sembolova ${ }^{3}$, \\ Lenka Sochorova ${ }^{1}$, Kamil Prokes ${ }^{1}$, Jiri Sochor ${ }^{1}$ \\ 1 Department of Viticulture and Enology, Mendel Univerzity in \\ Brno, Valticka 337, 69144 Lednice, Czech Republic \\ 2 Research Institute of Brewing and Malting, Lipova 15, 12044 \\ Prague, Czech Republic \\ 3 EPS biotechnology, s.r.o., V Pastouškách 205, 68604 Kunovice, \\ Czech Republic \\ * corresponding author: prusova.bozena@email.cz
}

\begin{abstract}
In this paper we focus on possibilities of using natural microflora from vineyards to enhance spontaneous fermentation. Obtained yeast isolates, naturally occurring in vineyards, which were previously isolated in 2017 and 2018, were used for inoculation of Hibernal grape must. Spontaneously fermented musts and musts with the yeast isolates from 2017 and 2018 were compared. Basic parameters of the musts (sugar concentration, pH, concentration of titratable acids, concentration of assimilated nitrogen) were analysed studied, and a sensory analysis of the resultant wines was performed. The fermentation with the yeast isolates was quick and smooth. In the spontaneous fermentation lower ethanol production rate was observed at the end of the fermentation process. During the sensory evaluation, fruitiness of the spontaneously fermented batch was lower, but its vegetal characteristic was pronounced. The variant with the yeast isolates from 2017 was described as smooth, and the variant with yeast isolates from 2018 was
\end{abstract} evaluated as slightly vegetal.

Keywords: spontaneous fermentation, yeast, yeast isolates, terroir

\section{Introduction}

Wine is a result of a complex microbial bioconversion of grape must in which various microorganisms participate (Liu et al., 2017). Of those microorganisms yeasts are the most important since they play a key role in the grape must conversion into wine. Their production of ethanol and other metabolites during alcohol fermentation (AF) phase substantially influences wine quality (Ciani et al., 2016). Selected strains of Saccharomyces cerevisiae are usually used as starting cultures that are useful for support and complete biological control of AF. Thanks to these strains of yeast, the fermentation process becomes controllable (Garofalo et al., 2016; Berbegal et al., 2017; Petruzzi et al., 2017).

During a spontaneous fermentation, musts are fermented by yeast species of natural microbiota of vine. In the beginning, apiculate wine yeasts comprise $99 \%$ of all the yeasts in the must, representing the natural microflo- ra of a grape. These yeasts start the fermentation process. They have the ability to ferment must with a concentration of alcohol of up to $5 \%$. After that, more resistant yeasts of the Saccharomyces cerevisiae species take over this function. Some suggest that the Saccharomyces cerevisiae yeast do not live in nature and that they occur only in viticulture instead (Martini, 1993). However, it was confirmed that the Saccharomyces cerevisiae yeasts occur in grapes and enter the fermentation process with must (Polsinelli et al., 1996; Török et al., 1996). The advantage of non-Saccharomyces yeasts is the speed of the exponential phase of growth and their enzymatic equipment. Thanks to this, these yeasts influence the aromatic properties of fermenting wines differently. However, the quality and diversity of the resulting wines do not originate in spontaneous fermentation in wine cellars, but in a vineyard. Bacterial communities present in a particu- 
lar vineyard can affect the sensory properties of grapes and the resulting wines. Bacterial communities in the soil are significantly different from communities settling on plant surfaces (canes, leaves, blossoms and grapes). The soil bacteria related to roots significantly influence plant growth and nutrition. The location of vineyards is always characterized by soil microbiome. Zarraonaindia et al. (2015) suggest that, primarily, the soil and its microorganisms affect the amount and species of individual yeasts in grapes and, because of their character, allow the production of the so-called terroir wines.

Spontaneous fermentation is the oldest process of wine production; its suppression led to a development of technical microbiology and a pursuit to unify and standardise production. The unique taste of a product, which attracts consumers, makes them buy the product and repurchase it, is specific thanks to the fermentation process. In past years, studies have focused on the influence of microorganisms (not only yeasts) on the sensory properties of wine (Vigentini et al., 2015; Zarraonaindia et al., 2015). The effect of the vineyard environment is perceived as essential for the wine characteristics. It significantly overshadows the influence of biological factors, assuming that the cultural wine yeasts of the Saccharomyces genus and other microorganisms can metabolically leave chemical traces in a wine bouquet. It is assumed that if the microorganisms are not intentionally inoculated, they originate from the grapes themselves (Mortimer et al., 1999). Some microorganisms may also come from viticultural equipment (Bokulich et al., 2013).

Earlier studies independently suggest the rarity of the Saccharomyces cerevisiae species on grapes and, conversely, its majority during alcohol fermentation. Studies focusing on a distribution of several strains of Saccharomyces cerevisiae during wine production (Bouix et al., 1981) using various identification methods, identified different strains of Saccharomyces cerevisiae, which were found not only on grapes and but also on walls or floors in wine cellars. These were the same yeasts that occurred in harvest containers, pressers and on pickers' hands. Common methods for yeast identification have been known since long ago. They may range from mitochondrial DNA analysis, pulsed-field gel electrophoresis to MALDI-TOF (matrix assisted laser desorption/ionisation coupled with time-of-flight mass spectrometry) analysis of ribosomal proteins (Hudspeth et al., 1980; Hwang-Lee et al., 1983; Schwartz et al., 1984). It has been proven many times that there is a huge genetic diversity in the strains of Saccharomyces cerevisiae (Dubourdieu et al., 1987; Blondin et al., 1988; Hallet et al., 1988; Dubourdieu et al., 1990; Portugal et al., 2015).
Zarraonaindia et al. (2015) provide evidence that the microbial communities on grapes and those in must are most similar compared to other sources of wine-making microbes. This suggests that a pre-fermentation plant community remains relatively stable, or at least more stable than a community among plant organs. Pretorius et al. (1999) found that the presence or absence of Saccharomyces cerevisiae can be different for every plant and grape. The diversity and quantity of the microbiological population is also influenced by weather conditions, such as temperature, UV radiation, rainfall, sunlight, wind as well as the method of vineyard treatment (Chamberlain et al., 1997; Barata et al., 2012). The importance of the autochthonous population presence on grapes and during fermentation is generally known (Fleet, 2003; Barata et al., 2012). For this reason, it is not always possible to obtain the same end product from spontaneous fermentation. This issue is currently solved using commercial yeast strains in the fermentation process, however, at the expense of the autochthonous characteristics of wine (Clemente-Jimenez et al., 2004).

This paper is focused on monitoring the effects of two consortia of wine microorganisms obtained from spontaneous fermentations in 2017 (variant b) and 2018 (variant c), compared with direct spontaneous fermentation without inoculation of any consortium (variant a). This paper is one of a few studies dealing with the characterisation of microorganism consortia in wine (Bokulich et al., 2012; Bokulich et al., 2016; Marzano et al., 2016).

\section{Material and Methods}

\subsection{Cultivation media}

MEA+T Agar (Sigma-Aldrich, Germany): Nutrient medium from wort agar supplemented with tetracycline (a broad-spectrum antibiotic against both G+ and G- bacteria). Only eukaryotic microorganisms grow on this medium.

WLN (Sigma-Aldrich, Germany): Nutrient agar for counting and culturing yeast and bacteria. Composition: agar 20 g. $\mathrm{L}^{-1}$, bromocresol green 0.022 g. $\mathrm{L}^{-1}$, calcium chloride 0.125 g. $\mathrm{L}^{-1}$, casein enzymic hydrolysate 5 g.L $\mathrm{L}^{-1}$, dextrose 50 g. $\mathrm{L}^{-1}$

MRS (Sigma-Aldrich, Germany): Nutrient agar for the determination of lactic bacteria. Composition: Agar 12 g.L.diammonium bicarbonate 2 g. $L^{-1}$, potassium hydrogen phosphate 2 g. $\mathrm{L}^{-1}, \mathrm{D}(+)$ glucose 20 g. $\mathrm{L}^{-1}$, magnesium sulphate 0.1 g.L. ${ }^{-1}$, manganese sulphate 0.05 g.L. $\mathrm{L}^{-1}$, meat extract 5 g. $\mathrm{L}^{-1}$, sodium acetate 5 g. $\mathrm{L}^{-1}$, universal peptone 10 g. $\mathrm{L}^{-1}$, yeast extract 5 g.L. $\mathrm{L}^{-1}$. 
YPD (Sigma-Aldrich, Germany): Solid medium for yeast multiplication. Composition: Bacteriological peptone 20 g.L. $L^{-1}$, yeast extract 10 g.L. $\mathrm{L}^{-1}$, glucose 20 g. $\mathrm{L}^{-1}$, agar 15 g.L. $\mathrm{L}^{-1}$. ME (Sigma-Aldrich, Germany): Agar consists of tryptose; yeast extract; glucose; disodium hydrogen phosphate; sodium azide; 2,3,5-triphenyltetrazolium chloride; agar; and distilled or deionised water.

\subsection{Yeast consortia}

Consortia of wine microorganisms were separated from spontaneous fermentation of pressed grape must of $\mathrm{Hi}$ bernal grapevine variety. Due to the highest diversity of microorganisms, the most suitable sampling point for their isolation was the micro-sparkling point, when the first signs of fermentation were visually observed. During this case of spontaneous fermentation, $20 \mathrm{~mL}$ of the fermenting must was taken at the micro-sparkling point. The sample was subsequently diluted using the so-called decimal series (Koch dilution method). From each dilution $2 \mathrm{ml}$ were pipetted onto Petri dishes with MEA+T, WLN, and MRS culture medium, and a microbiological rod smear was performed. The Petri dishes were then placed in a thermostat $\left(30^{\circ} \mathrm{C}\right.$; WLN and MEA+T -3 days; MRS - 7 days, Table 1$)$.

At the end of the cultivation, the total number of microorganisms and individual colonies was counted based on a combined analysis of phenotypic characters.

\subsection{Growth characteristics}

Growth characteristics of individual isolates were determined after pre-cultivation in standard media (yeast - YPD; lactic acid bacteria - MRS) with the following culture conditions: $30^{\circ} \mathrm{C}$; shaking $120 \mathrm{rpm}$; yeast $24 \mathrm{~h}$; and lactic acid bacteria $72 \mathrm{~h}$.

The obtained cell suspensions were centrifuged (10 min; $10^{\circ} \mathrm{C} ; 10,000 \mathrm{rpm}$ ), washed with saline solution, and then re-suspended in a selected media (yeast - YPD, ME, YPDmod; lactic acid bacteria - MRS, YPD, and YPDmod) so that the resulting optical density value of the suspension was 0.2 at a wavelength of $600 \mathrm{~nm}$.

The obtained suspension was then pipetted onto Bioscreen C culture plates (Oy Growth Curves Ab Ltd). Each arrangement (microorganism x medium) consisted of five repetitions to ensure that relevant results are achieved. The culture conditions of the Bioscreen $\mathrm{C}$ device were set as follows: $30^{\circ} \mathrm{C}$; shaking every 3 mins; duration of one shaking cycle = $1 \mathrm{~min}$; and the so-called wide band of wavelengths - WB (420-620 nm). The maximum growth rate $\mu\left(\mathrm{h}^{-1}\right)$ was then calculated from the measured data of optical density from the growth curve, and the maximum optical density ODMAX was determined. These data, along with the shape of the growth curves, served to assign culture media to individual isolates.

\subsection{MALDI TOF analysis}

The MALDI TOF method was used to identify present microorganisms. It is a very accurate and simple method which is able to determine high molecular weight substances, proteins, peptides, lipids, nucleic acids, carbohydrates (Huong et al., 2014).

An essential part of the MALDI TOF measurement was the preparation of fresh $\alpha$-cyano-4-hydroxycinnamic acid. The organic solvent was prepared by mixing $500 \mu \mathrm{L}$ of acetonitrile (100\%), $475 \mu \mathrm{L}$ of distilled water and $25 \mu \mathrm{L}$ of trifluoroacetic acid. Before use, $250 \mu \mathrm{L}$ of organic solvent was added to a plastic tube. The contents of the tube were vortexed until complete dissolution of the crystals. $\alpha$-Cyano-4-hydroxycinnamic acid was stored in a dark place; it is ideal to prepare it one day before the measurement.

The cultures were applied to a clean metal plate for MALDI TOF and the culture was set to dry on the plate. It was then covered with 1 microliter of $\alpha$-cyano-4-hydroxycinnamic acid. At the same time it was important to homogenize the sample and the matrix (Jarolímková, 2017).

Unlike the analysis of bacteria, preprocessing of the yeast isolates was required to extract fungal proteins. The protein extraction method used to process yeast isolates for MALDI-TOF MS was adapted directly from established methods used to identify difficult bacterial isolates. Specifically 1 to 5 colonies of an isolate were inactivated in $75 \%$ ethanol, pelleted, and then suspended in a 1:1 mixture of $70 \%$ formic acid and acetonitrile. The resulting supernatant was then analyzed by MALDI-TOF MS (Marklein et al., 2009; Bader et al., 2011; Dhiman et al., 2011).

\subsection{Cultivation of individual isolates}

The aim of this procedure was to cultivate individual isolates of technologically important microorganisms and preserve them using the lyophilisation method. A separate cultivation of individual microbial isolates was performed on the basis of the information obtained from the growth characteristics. Individual taxa were first pre-cultured in $250 \mathrm{~mL}$ Erlenmeyer flasks $(100 \mathrm{~mL}$ medium volume; orbital stirring $120 \mathrm{rpm} ; 20^{\circ} \mathrm{C}$ ). The media for microorganisms are shown in Table 1 . The pre-cultured cell suspension was examined microscopically (cell morphology, elimination of contamination) and centrifuged $\left(10,000 \mathrm{rpm} ; 10 \mathrm{~min} ; 10^{\circ} \mathrm{C}\right)$.

After separating the supernatant, the pellet was washed with saline solution and re-centrifuged $\left(10,000 \mathrm{rpm} ; 10 \mathrm{~min} ; 10{ }^{\circ} \mathrm{C}\right)$ and re-suspended in pure culture medium. The prepared suspension served as the inoculum for the second cultivation stage, which was carried out in 2,000 mL Erlenmeyer flasks $(1,000 \mathrm{~mL}$ medium volume; orbital stirring at $100 \mathrm{rpm} ; 30^{\circ} \mathrm{C}$ ). 
After the cultivation was complete, the suspension was repeatedly centrifuged and washed as described in the previous step. The obtained biomass was mixed with cryoprotective medium (maltodextrin) and shock-frozen $\left(70{ }^{\circ} \mathrm{C} ; 24 \mathrm{~h}\right)$. The frozen suspension was then lyophilised. The viability of the obtained dehydrated biomass was then determined, and according to the qualitative and quantitative microbiological analysis and the cell viability in the lyophilisate, the CWM2017 (variant b) and CWM 2018 (variant c) consortia were compiled.

Table 1 Taxonomic identification, culture medium and cultivation time of microorganisms in consortia

\begin{tabular}{|c|c|c|}
\hline Taxonomic identification & $\begin{array}{c}\text { Culture } \\
\text { medium }\end{array}$ & $\begin{array}{c}\text { Cultivation } \\
\text { time (h) }\end{array}$ \\
\hline Lactobacillus brevis & MRS & 32 \\
\hline Lactobacillus plantarum & MRS & 48 \\
\hline Hanseniaspora gulliermondi & YPDm & 22 \\
\hline Saccharomyces cerevisiae 1 & YPDm & 36 \\
\hline Hanseniaspora uvarum 1 & YPD & 9 \\
\hline Hanseniaspora uvarum 2 & YPD & 17 \\
\hline Saccharomyces cerevisiae 2 & YPDm & 24 \\
\hline Zygosaccharomyces bailii & YPD & 12 \\
\hline Candida sake & YPD & 10 \\
\hline
\end{tabular}

Mass representation of individual isolates contained in the consortia of 2017 and 2018 are presented in Table 2 and Table 3. Two different axenic cultures of $S$. cerevisiae, designated I and II, three clones of Lactobacillus brevis, designated I, II and III, and two clones of Lactobacillus plantarum, designated I and II, were isolated.

Table 2 Mass representation of individual isolates in CWM 2017 (variant b)

\begin{tabular}{|c|c|}
\hline \multicolumn{2}{|c|}{ CWM 2017 } \\
\hline Taxonomic identification & \% w/w \\
\hline Saccharomyces cerevisiae & 59.3 \\
\hline Hanseniaspora uvarum & 19.9 \\
\hline Candida sake & 19.8 \\
\hline Lactobacillus plantarum I & 0.3 \\
\hline Lactobacillus brevis I & 0.2 \\
\hline Lactobacillus brevis II & 0.2 \\
\hline Lactobacillus brevis III & 0.2 \\
\hline Lactobacillus plantarum II & 0.1 \\
\hline
\end{tabular}

Table 3 Mass representation of individual isolates in CWM 2018 (variant c)

\begin{tabular}{|c|c|}
\hline \multicolumn{2}{|c|}{ CWM 2018 } \\
\hline Taxonomic identification & \% w/w \\
\hline Lactobacillus brevis & 3.6 \\
\hline Lactobacillus plantarum & 3.1 \\
\hline Hanseniaspora gulliermondi & 0.8 \\
\hline Saccharomyces cerevisiae I & 3.4 \\
\hline Hanseniaspora uvarum I & 28.1 \\
\hline Hanseniaspora uvarum II & 5.4 \\
\hline Saccharomyces cerevisiae II & 3.4 \\
\hline Zygosaccharomyces bailii & 24.4 \\
\hline Candida sake & 27.9 \\
\hline
\end{tabular}

\subsection{Fermentation trials}

It is assumed that the grapes after harvest already contain their own microflora, and that there is possibility to support the spontaneous fermentation by the previously isolated microbial consortium.

For this purpose, three trial fermentations were performed:

\section{Variant a}

- spontaneous fermentation of must harvested in 2019;

\section{Variant b}

- inoculation by a consortium of yeasts obtained in 2017; Variant c

- inoculation by a consortium of yeasts obtained in 2018 .

Individual yeast isolates were initially cultured in $50 \mathrm{~mL}$ Erlenmeyer flasks (25 mL medium volume; orbital stirring at $120 \mathrm{rpm} ; 30^{\circ} \mathrm{C}$ ). The media and the culture times used for the individual isolates are shown in (Table 1). In the obtained cell suspension, the cell density was determined by microscopic cell counting in a Bürker chamber. The calculated amount of this suspension was then pipetted into a final concentration of $10^{8}$ cells. $\mathrm{mL}^{-1}$ in a $250 \mathrm{~mL}$ Erlenmeyer flask (100 mL YPDm medium volume; without shaking; $25^{\circ} \mathrm{C}$ ). Fermentation was monitored by the gravimetric method; weight loss due to the metabolic conversion of fermentable sugars to carbon dioxide and ethanol was observed.

For the experimental batch, a Hibernal variety was chosen (the variety was bred in Germany, 1944, a crossbreed of Seibel variety 7053 (Chancellor) and Riesling). The harvested grapes were crushed immediately after delivery to the processing plant and destemmed by an electric stainless steel destemmer (Enoitalia, Italy). The acquired must was immediately pressed in a pneumatic press with a volume of $1200 \mathrm{~L}$ (Wottle, Austria). Approximately $320 \mathrm{~L}$ of must was acquired from $500 \mathrm{~kg}$ of grapes. The pressed must was clarified through sedimentation (after $24 \mathrm{~h}, 16^{\circ} \mathrm{C}$ ). 
The turbidity value after clarification was approximately 400 NTU. Regarding the low sugar content, the grape must was treated by addition of sucrose to final concentration of reducing sugars $19^{\circ} \mathrm{NM}$ (3.3 $\mathrm{kg}$ sucrose per $100 \mathrm{~L}$ of must). The prepared must was further divided into three parts, with about $100 \mathrm{~L}$ of volume in each. The first part was used for the experimental batch fermented by spontaneous microflora, the second for the batch fermented by the CWM 2017 (variant b) and the third for fermentation by the CWM 2018 (variant c), obtained during the past years of the experiment. For optimal results, sterile microfiltered grape must was used and the inoculated variants were compared to the spontaneous fermentation under the same conditions as the inoculated variants.

Inoculation of each variant was performed using lyophilized consortia CWM17 (variant a) and CWM18 (variant b). Amount of $30 \mathrm{~g}$ consortia, were individually stirred in a mixture containing $500 \mathrm{~mL}$ of sterilized grape must and $500 \mathrm{ml}$ of water under a temperature of approximately $30^{\circ} \mathrm{C}$. After 5 hours, the yeast starter was added into the total volume of prepared must.

After fermentation (14 days), the wine variants were racked to remove coarse materials and returned to clean containers with a pump. A $30 \mathrm{mg} \cdot \mathrm{L}^{-1}$ dose of $\mathrm{SO}_{2}$ was also added. The wine was left to sediment and, for the needs of sensory analysis, the concentration of free $\mathrm{SO}_{2}$ was kept between 25-30 mg. $\mathrm{L}^{-1}$. The wine was left without access to air in an inert container.

\subsection{Basic chemical parameters of must and wines}

The sugar concentration was determined by a refractometer (Atago, Japan). Brix scale was converted to ${ }^{\circ} \mathrm{NM}$.

The $\mathrm{pH}$ value was estimated in an undiluted sample using a pH-meter WTW pH 526 and SenTix 21 pH electrode (WTW, Germany). The total acidity (EEC No 2676/90) was determined in a TITROLINE EASY automatic titrator (manufacturer SI Analytics GmbH, Germany). Titrations were performed with $\mathrm{NaOH}\left(0.1 \mathrm{~mol} . \mathrm{L}^{-1}\right)$ as the titration reagent, using a SenTix $21 \mathrm{pH}$ electrode. Sample $(10 \mathrm{~mL})$ was diluted with $10 \mathrm{~mL}$ of distilled water, and titrated up to pH 8.1 because of a subsequent formol titration. The consumption of $\mathrm{NaOH}$ solution was calculated and total acidity was expressed as equivalents of tartaric acid in g.L-1 $\mathrm{L}^{-1}$. At the end of the titration, $5 \mathrm{~mL}$ of formaldehyde was added, the $\mathrm{pH}$ dropped, and the titration continued to the $\mathrm{pH}$ 8.1. The resulting consumption of $\mathrm{NaOH}$ indicates the amount of assimilable nitrogen in the must (mg. $\left.\mathrm{L}^{-1}\right)$ (Balík, 2011).

The analytical parameters of the must and fermenting wine were monitored using an ALPHA analyzer (Bruker, Germany). The ALPHA spectrometer is a compact FTIR analyzer based on the principle of ATR sampling (Bauer et al., 2008).This method of sampling allows the must or wine samples to be analyzed directly. Prior to the measuring of the first sample, the apparatus was thoroughly rinsed with distilled water and the background was measured using deionized water as a blank sample. For analyses $1 \mathrm{~mL}$ of sample was sampled with a syringe. The grape must/wine was centrifuged and $\mathrm{CO}_{2}$ from the fermenting must was removed using an ultrasonic bath. Depending on the method of calibration (must/wine/ fermenting wine), the recorded data were automatically software-evaluated and tabulated (OPUS wine).

\subsection{Sensory analysis}

The wines were evaluated by five tasters who are certified expert assessors for the sensory analysis of wine, according to ISO 8586:2012 (Standardization, 2012). All variants were assessed using the 100 -point scale according to the International Union of Oenologists IUOE.

The last category of the sensory evaluation was the assessment of the aromatic and mightiness profiles. Three pairs of opposite characteristics were evaluated. The taster only selected one from each pair and rated it on a scale of one to five:

- Oxidative versus reductive;

- Herbaceous, tannic versus soft, smooth;

- Fruity, ester versus vinous, waxy.

\subsection{Statistical analysis}

Statistical analyses and figures were generated using Excel 2007 software packages (manufactured by Microsoft Office, USA) and Statistica 10 statistical software (Copyright (C) StatSoft). A SD standard deviation from the total number of three trials was calculated.

\section{Results and discussion}

\subsection{Fermentation trials}

Before starting the fermentation process, the initial analytical parameters of the must were determined. The results are presented in Table 4. Regarding the low sugar concentration $16^{\circ} \mathrm{NM}$ and the associated risk for instability of the resulting wine, the grape must was treated by adding sucrose to the final concentration of reducing sugars $19^{\circ} \mathrm{NM}$. The assimilable nitrogen content $321 \mathrm{mg} . \mathrm{L}^{-1}$ was sufficient, so supplementary nutrition was not necessary.

During the whole fermentation process, alcohol concentration, sugars and $\mathrm{pH}$ were monitored. Samples were taken on the $6^{\text {th }}, 9^{\text {th }}, 12^{\text {th }}$ and $14^{\text {th }}$ day of the fermentation. The results are presented in Figures 1, 2 and 3 and in Table 5. 
Compared to the spontaneous fermentation, a smoother fermentation can be observed in the variants inoculated by the consortia. Figure 1 illustrates evolution of the alcohol concentration in the spontaneously fermented must in comparison with the must fermented with the CWM 2017 (variant b) and CWM 2018 (variant c) consortia. In the case of the spontaneous fermentation, a lower ethanol production rate can be seen on the 9th day of the fermentation and a higher concentration of reducing sugars was observed in this variant.

Figure 2 illustrates the evolution of the reducing sugars content during the spontaneous fermentation and the fermentation with the CWM 2017 (variant b) and CWM 2018 (variant c) consortia.

Significant differences between the variants inoculated with the consortia within the progress of fermentation were not observed. The differences were observed only in the resulting wine when the concentrations of the reducing sugars were 0.69 g.L $\mathrm{L}^{-1}$ in the spontaneous fermentation, 1.35 g.L $\mathrm{L}^{-1}$ in CWM 2017 (variant b) and 3.30 g. $\mathrm{L}^{-1}$ in the CWM 2018 (variant c). The alcohol concentration ranged from $11.33 \% \mathrm{v} / \mathrm{v}$ in CWM 2018 (variant c) to $11.72 \% \mathrm{v} / \mathrm{v}$ in CWM 2017 (variant b) (Table 2).

The $\mathrm{pH}$ values were different in all the variants during the fermentation. Figure 3 illustrates the evolution of the $\mathrm{pH}$ value during the fermentation process. The spontaneous fermentation and CWM 2018 (variant c) had a pH value of 3.5 over the first 11 days, compared with the higher $\mathrm{pH}$ for CWM 2017(variant b), at 3.55 . From the $12^{\text {th }}$ day, the $\mathrm{pH}$ increased to 3.6 for the spontaneous fermentation and CWM 2017(variant b) and to 3.65 for CWM 2018 (variant c). These values can be affected by yeast by-products occurring during fermentation and by the activity of lactic acid bacteria at the end of the alcohol fermentation process.

Three groups of microorganisms are generally present in wine during fermentation: the initial phase contains apiculate yeast, the main phase is related to the growth of Saccharomyces yeasts, and the third is related to lactic acid bacteria participating in malolactic fermentation. Thus, the wine's quality is strongly dependent on the variety of species and strains in a microbial consortium, which is constantly developing during a wine-making process (Barata et al., 2012).

The spontaneous process of alcohol fermentation progressed without problems; however, a slower progress was observed in a higher alcohol concentration at the final stage of fermentation. This is confirmed
Table 4 Basic analytical parameters of the must before inoculation by consortia

\begin{tabular}{|c|c|c|c|}
\hline $\begin{array}{c}\text { Sugar } \\
\text { concentration }{ }^{\circ} \mathrm{NM}\end{array}$ & $\mathrm{pH}$ & Total acidity g. $\mathrm{L}^{-1}$ & YAN mg. $L^{-1}$ \\
\hline $16.0 \pm 0.0$ & $3.51 \pm 0.02$ & $6.48 \pm 0.11$ & $321 \pm 3$ \\
\hline
\end{tabular}

Note: $\quad$ YAN - yeast assimilable nitrogen

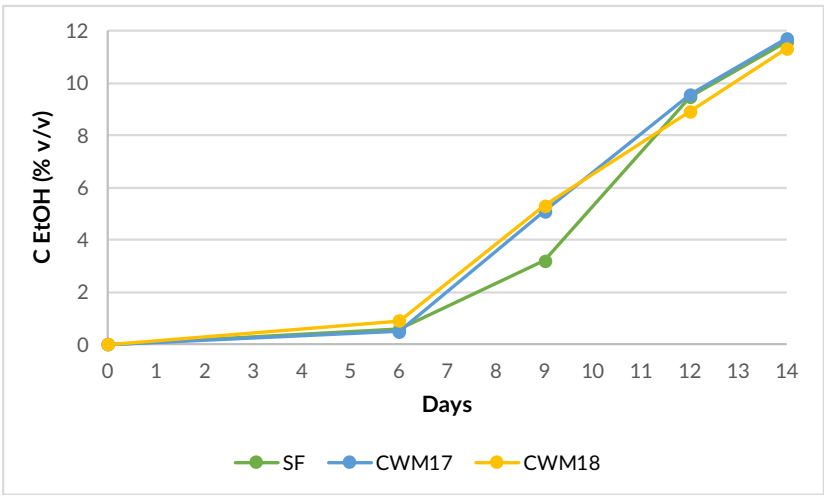

Figure 1 Evolution of alcohol concentration during trial fermentations: SF $=$ variant $a=$ spontaneous fermentation; $C W M 17=$ variant $b$ = consortium of wild microorganisms from 2017; CWM18 = variant $c=$ consortium of wild microorganisms from 2018.

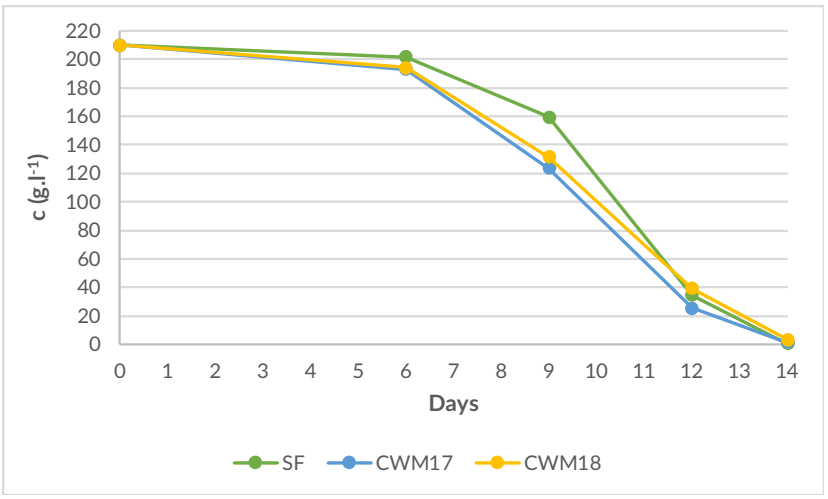

Figure 2 Consumption of reducing sugars during trial fermentations: SF $=$ variant $a=$ spontaneous fermentation; $C W M 17=$ variant $b$ = consortium of wild microorganisms from 2017; CWM18 = variant $c=$ consortium of wild microorganisms from 2018 .

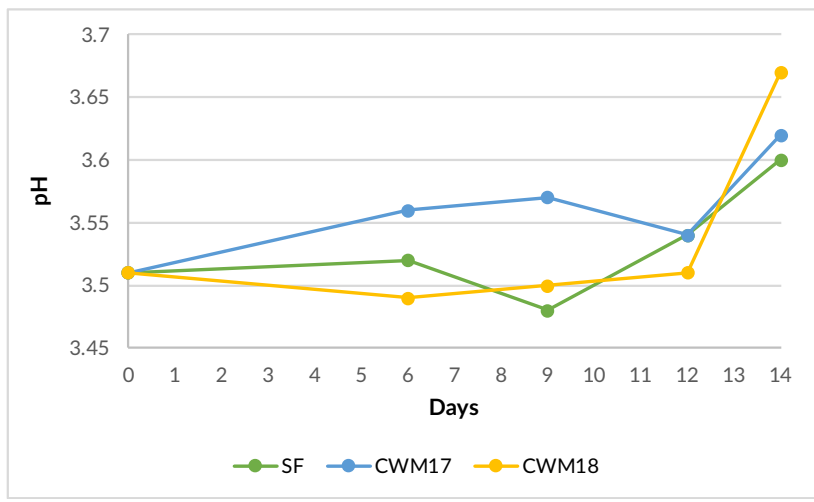

Figure 3 Monitoring of $\mathrm{pH}$ value during trial fermentations: $\mathrm{SF}=$ variant $a=$ spontaneous fermentation; CWM17 = variant $b$ = consortium of wild microorganisms from 2017; CWM18 = variant $c=$ consortium of wild microorganisms from 2018. 
Table 5 Basic parameters of the resulting wine for all batches

\begin{tabular}{|c|c|c|c|}
\hline & $\begin{array}{c}\text { Spontaneous fermentation } \\
\text { (variant a) }\end{array}$ & $\begin{array}{c}\text { CWM 2017 } \\
\text { (variant b) }\end{array}$ & $\begin{array}{c}\text { CWM 2018 } \\
\text { (variant c) }\end{array}$ \\
\hline Ethanol (\% v/v) & $11.59 \pm 0.13$ & $11.72 \pm 0.14$ & $11.33 \pm 0.12$ \\
\hline Red. sugars (g.L-1) & $0.69 \pm 0.09$ & $1.35 \pm 0.04$ & $3.30 \pm 0.14$ \\
\hline pH & $3.60 \pm 0.01$ & $3.62 \pm 0.01$ & $3.67 \pm 0.01$ \\
\hline Titr. acid (g.L-1) & $4.92 \pm 0.07$ & $4.96 \pm 0.04$ & $4.71 \pm 0.04$ \\
\hline Acetic acid (g.L-1) & $0.51 \pm 0.03$ & $0.45 \pm 0.02$ & $0.43 \pm 0.02$ \\
\hline
\end{tabular}

by Egli et al. (1998) in their study. A minimum amount of reducing sugars remained in the wine. The alcohol fermentation of CWM 2017 (variant b) and CWM 2018 (variant c) was quick and smooth. The CWM 2018 (variant c) contained the highest concentration of reducing sugars compared with CWM 2017 (variant b) and the spontaneous fermentation. The total acidity ranged from $4.71 \mathrm{~g}^{-\mathrm{L}^{-1}}$ to $4.96 \mathrm{~g} . \mathrm{L}^{-1}$, and the concentration of the acetic acid ranged from 0.43 g.L $\mathrm{L}^{-1}$ in CWM 2018 (variant c) to 0.51 g. $\mathrm{L}^{-1}$ in the spontaneous fermentation (variant a).

The fermentation of all variants lasted for 14 days. The progress of the fermentation by individual consortia did not significantly differ, except in the case of the spontaneous fermentation (variant a) in which a lower ethanol production rate was observed on the $9^{\text {th }}$ day. Regarding the CWM 2017 (variant b) and CWM 2018 (variant c), the signs of the initial process of alcohol fermentation were observed on the $6^{\text {th }}$ day after the inoculation. The beginning of the spontaneous fermentation (variant a) was delayed starting on the $7^{\text {th }}$ day. The start of the fermentation process was slightly slower for the spontaneous fermentation (variant a); however, further fermentation progress was almost identical for all the samples.

This fact is also confirmed by previous studies that show smoother fermentation progress using the Saccharomyces yeast (Egli et al., 1998; Pretorius et al., 1999; Fleet, 2003). The prediction of the yeast population in the spontaneous fermentation is difficult to achieve. For this reason, there is a risk of profiling non-Saccharomyces strains, depending on the fermentation conditions, and a risk of stuck fermentation. This phenomenon is related to the lower capability of the apiculate yeast to ferment alcohol. For most apiculate strains, this capability equates to only a 6-7\% v/v of alcohol, while the Saccharomyces yeasts can ferment sugar up to a $12-14 \% \mathrm{v} / \mathrm{v}$ (Martini, 1993).

\subsection{Sensory analysis}

Most aromatic wine compounds, including the variety that is generally synthesised in grapes, are produced or released during a wine-making process and they are greatly affected by the microbial activity of yeasts and bacteria contained in the wine (Liu et al., 2017). The consortium of microorganisms, including yeasts and bacteria in the vineyards, is dependent on many factors, known collectively as terroir, but it can also be affected by the conditions of fermentation (Bokulich et al., 2014; Gilbert et al., 2014; Zarraonaindia et al., 2015).

Although differences during fermentation were not significant due to the use of similar yeasts, there were differences in aromatic profiles of the variants, which were detected through the sensory assessment of the resulting wines. The spontaneously fermented (variant a) was assessed as the best within this study because it overshadowed the other samples in the category of taste harmony. The variant fermented with the 2017 consortium (variant b) was evaluated as the worst. The reason for this may be the dominance of the yeast strain that has the best properties for fermentation but produces less sensory-positive substances.

Table 6 contains average values of all ratings evaluated sensorially according to the UIOE 100 -point scale.

The spontaneous fermentation (variant a) overshadowed the other samples, especially in the category of taste harmony. The variant a had the highest score of 87.4 points, the CWM 2018 (variant c) had 86 points and the CWM 2017 (variant b) had 85.2 points.

The evaluation of the aromatic profile, structure and mightiness was performed on the scale of 1 to 10 , with 1 as the least and 10 as the most. Figures 4 and 5 show the average values of all the evaluations.

The spontaneously fermented (variant a) had the most intense taste and was assessed as the most complex and most corpulent wine with dominant herbaceous, spicy and mineral tones. The variants inoculated by the consortia were described as similar to each other with intense aromas featuring spicy and herbaceous tones. However, the sample inoculated with the CWM 2018 (variant c) consortium was evaluated as the more intense wine. Flowery, tropical and citrus fruit tones were evaluated in all three samples. Minor differences in the sensory assessment confirm the influence of microorganism strains on 
Table 6 100-Point scale for sensory evaluation of the experimental batches

\begin{tabular}{|c|c|c|c|}
\hline Variant & $\begin{array}{c}\text { Spontaneous } \\
\text { (variant a) }\end{array}$ & $\begin{array}{c}\text { CWM 2017 } \\
\text { (variant b) }\end{array}$ & $\begin{array}{c}\text { CWM 2018 } \\
\text { (variant c) }\end{array}$ \\
\hline Clarity & 5.0 & 5.0 & 5.0 \\
\hline Colour & 10.0 & 10.0 & 10.0 \\
\hline Aroma intensity & 7.0 & 7.0 & 7.0 \\
\hline Aroma clarity & 4.8 & 4.8 & 5.0 \\
\hline Aroma harmony & 14.0 & 13.6 & 14.0 \\
\hline Taste intensity & 7.0 & 6.4 & 7.0 \\
\hline Taste purity & 4.6 & 4.4 & 4.6 \\
\hline Taste harmony & 18.4 & 17.2 & 16.6 \\
\hline Persistence & 6.8 & 7.0 & 6.8 \\
\hline Overall impression & 9.8 & 9.8 & 10.0 \\
\hline Total points & $\mathbf{8 7 . 4 \pm 0 . 5}$ & $\mathbf{8 5 . 2 \pm 0 . 4}$ & $86.0 \pm 0.3$ \\
\hline
\end{tabular}

the resulting wine quality. Amongst others, this is also affected by vintage and weather conditions, that participate in both the structure of microorganisms and the aromatic substances produced in grapes. These substances are mainly affected by the temperature, the amount of precipitation and sunlight. This paper eliminates these effects by performing the experiment on one vintage wine, which further examines the influence of the consortia obtained in previous years. Some differences in the aromatic profile can be observed, which can be attributed to the individual yeast strains. This has been confirmed in many studies, such as the study by Clemente-Jimenez et. al. (2004), who state that it is not always possible to obtain the same product from spontaneous wine fermentation. This issue is currently solved by using commercial yeast strains in the fermentation process at the expense of the autochthonal character of wine, as a significant manifestation of yeast metabolism can cause some kind of wine uniformity (Chamberlain et al., 1997; Clemente-Jimenez et al., 2004;

\section{Aromatic profile}

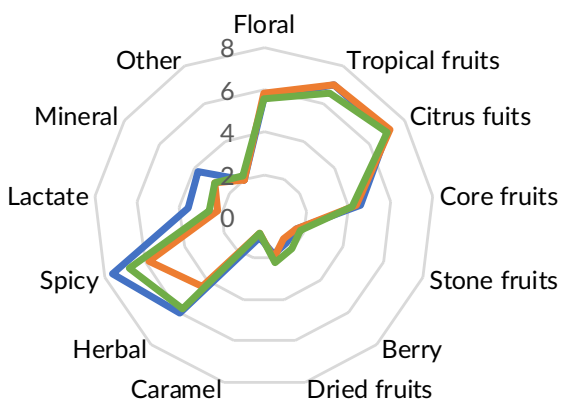

Spontaneous

Consortium 17

Consortium 18

Figure 5 The evaluation of the aromatic profiles of the experimental batches
Barata et al., 2012).

The last category of the sensory evaluation was the assessment of the aromatic and mightiness profiles. Three pairs of contradictory characteristics were evaluated: "oxidative versus reductive", "herbaceous, tannic versus soft, smooth" and "fruity, ester versus vinous, waxy".

Figure 6 shows average values of all the assessments. All the evaluated samples were described as rather reductive. The samples fermented with the consortia were assessed as very fruity. For the batch fermented spontaneously (variant a), the fruitiness was assessed as being lower, however, its herbaceous character was identified. The 2017 consortium was described as soft, and the 2018 consortium was assessed as slightly herbaceous.

Recent results suggest that a microbial profile of grapes can predict the structure and amount of some metabolites. In some cases, these predictions, based on sta-

\section{Structure and mightiness}

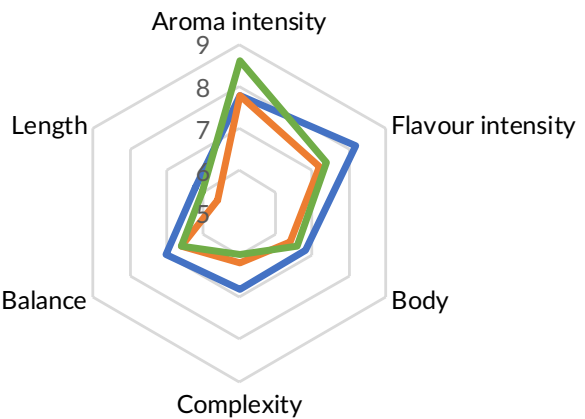

Spontaneous

Consortium 17

Consortium 18

Figure 4 The comparison of the structure and mightiness of the experimental batches

\section{Aromatic and mightiness profiles}

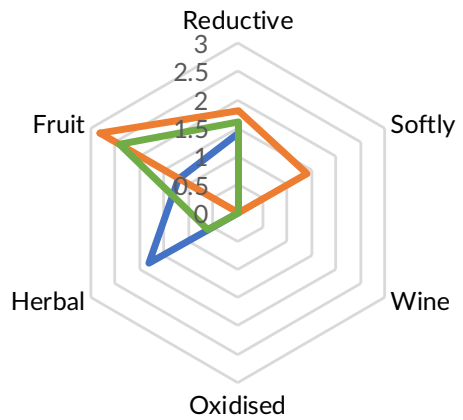

Spontaneous

Consortium 17

Consortium 18

Figure 6 The comparison of the aromatic and mightiness profiles of the experimental batches 
tistical models, can be confirmed by the metabolic characteristics of some microorganisms that were previously studied as a pure inoculum. There are many microbial species with a potential occurrence in wine (Belda et al., 2016; Bokulich et al., 2016), although their specific role during wine-making is not clearly understood. Antagonistic relationships between individual microorganisms, which cannot be fully predicted in advance, can appear. This fact is also proven by the results of this study whereby even within the gaining of one consortium, which characterises a vineyard, interactions with another grape microflora appear. Aromatic compounds produced during fermentation generally represent the highest percentage of the overall aromatic structure of wine. The alcohol fermentation that is mainly completed by Saccharomyces cerevisiae leads to the production of higher amounts of alcohols and esters (Álvarez-Pérez et al., 2012).

Most fermentation aromatic compounds have high sensory thresholds, so they do not significantly contribute to the distinctive aroma of wine. However, the combination creates the basic matrix of a wine aroma. The highest aroma-influencing substances are present in lower concentrations in grapes and wines; even with very low (ng.L1) sensory thresholds, they can have a significant impact on the overall aroma of the wine. In many cases, the production of higher amounts of alcohols and esters is connected with the interlocked metabolic routes of the main yeast strain's metabolism. Conversely, the release of some compounds (such as various terpenes or thiols, which are released from bound form by yeast activity) depends on the activity of individual yeast enzymes (Baroň et al., 2012). Regarding the complexity of wine aroma, the study of volatile wine substances requires the performance of complex and expensive chromatographic-spectrometric analysis (Campbell-Sills et al., 2016).

\section{Conclusion}

The aim of this study was to compare consortia of wine microorganisms obtained from the same vineyard over the past two years with spontaneous fermentation. The inoculation by this mixed culture supports the 'terroir' of a given vineyard and helps to avoid problems with slow fermentation.

The consortia of wine microorganisms obtained from the spontaneous fermentation of two consecutive years were used for the fermentation of one Hibernal variety in this study and were compared with spontaneous fermentation of must pressed from Hibernal harvested in 2019. Although the differences during fermentation were not significant, there were perceptible differences in the aromatic profiles within the sensory assessment of the resulting wines.

The spontaneously fermented variant was assessed as the best within this study because it overshadowed other samples in the category of taste harmony. The variant fermented with the 2017 consortium was evaluated as the worst. The reason for this may be the dominance of the yeast strain, which has the best properties for fermentation but produces less sensory-positive substances.

The spontaneously fermented variant had the most intense taste and was assessed as the most complex and most corpulent, with dominant herbaceous, spicy and mineral tones. The variants inoculated by the consortium were described as similar, with an intense aroma featuring spicy and herbaceous tones. However, the sample inoculated with the 2018 consortium was evaluated as the more intense one. Flowery tones and tropical and citrus fruit tones were identified for all three samples.

All the samples were assessed and described in a relatively similar manner. However, the batches fermented with the consortia were more similar to each other than the spontaneously fermented batch. The consortium samples were assessed as having slightly different characteristics for some descriptors.

\section{Acknowledgement}

The authors of the paper highly appreciate the financial support from IGA - ZF/2019 - DP002 and TAČR TH02030280-2018V002 projects.

\section{References}

Álvarez-Pérez, J. M., Campo, E., San-Juan, F., Coque, J. J. R., Ferreira, V. and Hernández-Orte, P. (2012). Sensory and chemical characterisation of the aroma of Prieto Picudo rosé wines: The differential role of autochthonous yeast strains on aroma profiles. Food Chemistry, 133 (2), 284-292. https://doi.org/10.1016/j.foodchem.2012.01.024

Bader, O., Weig, M., Taverne-Ghadwal, L., Lugert, R., Gross, U. and Kuhns, M. (2011). Improved clinical laboratory identification of human pathogenic yeasts by matrix-assisted laser desorption ionization time-offlight mass spectrometry. Clinical Microbiology and Infection, 17 (9), 1359-1365. https://doi.org/10.1111/j.1469-0691.2010.03398.x

Balík, J. (2011). Vinařství: návody do laboratorních cvičení (Winery, instructions for laboratory excercises.), Mendelova zemědělská a lesnická univerzita, Brno, ISBN 80-7157-809-6.

Barata, A., Malfeito-Ferreira, M. and Loureiro, V. (2012). The microbial ecology of wine grape berries. International Journal of Food Microbiology, 153 (3), 243-259. https://doi.org/10.1016/j.ijfoodmicro.2011.11.025

Baroň, M. and Fiala, J. (2012). Chasing after minerality, relationship to yeasts nutritional stress and succinic acid production. Czech Journal of Food Sciences, 30 (2), 188-193. https://doi. org/10.17221/464/2010-CJFS

Bauer, R., Nieuwoudt, H., Bauer, F. F., Kossmann, J., Koch, K. R. and Esbensen, 
K. H. (2008). FTIR spectroscopy for grape and wine analysis. Analytical Chemistry, 80 (5), 1371-1379. https://doi.org/10.1021/ac086051c

Belda, I., Ruiz, J., Alastruey-Izquierdo, A., Navascués, E., Marquina, D. and Santos, A. (2016). Unraveling the enzymatic basis of wine "flavorome": a phylo-functional study of wine related yeast species. Frontiers in Microbiology, 7, 12. https://doi.org/10.3389/ fmicb.2016.00012

Berbegal, C., Spano, G., Tristezza, M., Grieco, F. and Capozzi, V. (2017). Microbial resources and innovation in the wine production sector. South African Journal of Enology and Viticulture, 38 (2), 156-166. https://doi.org/10.21548/38-2-1333

Blondin, B. and Vezinhet, F. (1988). Identification de souches de levures oenologiques par leurs caryotypes obtenus en électrophorèse en champ pulsé. Revue française d'oenologie, 28 (115), 7-11.

Bokulich, N. A., Collins, T. S., Masarweh, C., Allen, G., Heymann, H., Ebeler, S. E. and Mills, D. A. (2016). Associations among wine grape microbiome, metabolome, and fermentation behavior suggest microbial contribution to regional wine characteristics. mBio, 7 (3), e0063100616. https://doi.org/10.1128/mBio.00631-16

Bokulich, N. A., Joseph, C. L., Allen, G., Benson, A. K. and Mills, D. A. (2012). Next-generation sequencing reveals significant bacterial diversity of botrytized wine. PloS one, 7 (5), e36357. https://doi.org/10.1371/ journal.pone.0036357

Bokulich, N. A., Ohta, M., Richardson, P. M. and Mills, D. A. (2013). Monitoring seasonal changes in winery-resident microbiota. PloS one, 8 (6), e66437. https://doi.org/10.1371/journal.pone.0066437

Bokulich, N. A., Thorngate, J. H., Richardson, P. M. and Mills, D. A. (2014). Microbial biogeography of wine grapes is conditioned by cultivar, vintage, and climate. Proceedings of the National Academy of Sciences, 111 (1), E139-E148. https://doi.org/10.1073/pnas.1317377110

Bouix, M., Leveau, J. Y. and Cuinier, C. (1981). 14 - Applications de l'electrophorese des fractions exocellulaires de levures au controle de l'efficacite d'un levurage en vinification. Advances in Biotechnology (Proceedings of the Fifth International Yeast Symposium Held in London, Canada, July 20-25, 1980), pages 87-92. https://doi. org/10.1016/B978-0-08-025382-4.50019-8

Campbell-Sills, H., Capozzi, V., Romano, A., Cappellin, L., Spano, G., Breniaux, M., Lucas, P. and Biasioli, F. (2016). Advances in wine analysis by PTR-ToF-MS: Optimization of the method and discrimination of wines from different geographical origins and fermented with different malolactic starters. International Journal of Mass Spectrometry, 397, 42-51. https://doi.org/10.1016/j.ijms.2016.02.001

Ciani, M., Capece, A., Comitini, F., Canonico, L., Siesto, G. and Romano, P. (2016). Yeast interactions in inoculated wine fermentation. Frontiers in Microbiology, 7, 555. https://doi.org/10.3389/fmicb.2016.00555

Clemente-Jimenez, J. M. A., Mingorance-Cazorla, L., Martínez-Rodríguez, S., Las Heras-Vázquez, F. J. and Rodríguez-Vico, F. (2004). Molecular characterization and oenological properties of wine yeasts isolated during spontaneous fermentation of six varieties of grape must. Food Microbiology, 21 (2), 149-155. https://doi.org/10.1016/S07400020(03)00063-7

Commission Regulation (EEC) No 2676/90 of 17 September 1990 determining Community methods for the analysis of wines. Published 1990-09-17. Available from: https://op.europa.eu/en/ publication-detail/-/publication/6528497d-1ece-4355-ab08-c73b3242f7ee/language-en

Dhiman, N., Hall, L., Wohlfiel, S. L., Buckwalter, S. P. and Wengenack, N. L. (2011). Performance and cost analysis of matrix-assisted laser desorption ionization-time of flight mass spectrometry for routine identification of yeast. Journal of Clinical Microbiology, 49 (4), 16141616. https://doi.org/10.1128/JCM.02381-10

Dubourdieu, D. and Frezier, V. (1990). Application de l'electrophorèse en champs pulsés à l'étude de l'écologie des levures en fermentation spontanée. Revue française d'oenologie, 30 (125), 37-40.

Dubourdieu, D., Sokol, A., Zucca, J., Thalouarn, P., Dattee, A. and Aigle, M. (1987). Identification des souches de levures isolées de vins par l'analyse de leur ADN mitochondrial. OENO One, 21 (4), 267-278. https://oeno-one.eu/article/view/1286/1343

Egli, C., Edinger, W., Mitrakul, C. and Henick-Kling, T. (1998). Dynamics of indigenous and inoculated yeast populations and their effect on the sensory character of Riesling and Chardonnay wines. Journal of Applied Microbiology, 85 (5), 779-789. https://doi.org/10.1046/ j.1365-2672.1998.00521.x

Fleet, G. H. (2003). Yeast interactions and wine flavour. International Journal of Food Microbiology, 86 (1-2), 11-22. https://doi.org/10.1016/ S0168-1605(03)00245-9

Garofalo, C., Arena, M. P., Laddomada, B., Cappello, M. S., Bleve, G., Grieco, F., Beneduce, L., Berbegal, C., Spano, G. and Capozzi, V. (2016). Starter cultures for sparkling wine. Fermentation, 2 (4), 21. https://doi. org/10.3390/fermentation2040021

Gilbert, J. A., van der Lelie, D. and Zarraonaindia, I. (2014). Microbial terroir for wine grapes. Proceedings of the National Academy of Sciences, 111 (1), 5-6. https://doi.org/10.1073/pnas.1320471110

Hallet, J., Craneguy, B., Zucca, J. and Poulard, A. (1988). Caractérisation de différentes souches industrielles de levures oenologiques par les profils de restriction de leur ADN mitochondrial. Le Progrès agricole et viticole, 105 (13-14), 328-333.

Hudspeth, M. E., Shumard, D. S., Tatti, K. M. and Grossman, L. I. (1980). Rapid purification of yeast mitochondrial DNA in high yield. Biochimica et Biophysica Acta (BBA)-Nucleic Acids and Protein Synthesis, 610 (2), 221-228. https://doi.org/10.1016/0005-2787(80)90003-9

Huong, T. T., Komínková, M., Guráň, R., Ruttkay-Nedecký, B., Kopel, P., Trnková, L., Zitka, O., Adam, V. and Kizek, K. (2014). Identification of microorganisms by MALDI-TOF MS. Journal of Metallomics and Nanotechnologies, 1 (2), 64-66. Available from: http://web2.mendelu. cz/af_239_nanotech/J_Met_Nano/0214/pdf/d-microbial_identification_by_maldi-tof_ms.pdf

Hwang-Lee, L., Blamire, J. and Cottrell, S. F. (1983). A rapid procedure for the isolation of yeast mitochondrial DNA suitable for restriction fragment analysis. Analytical Biochemistry, 128 (1), 47-53. https://doi. org/10.1016/0003-2697(83)90342-1

Chamberlain, G., Husnik, J. and Subden, R. (1997). Freeze desiccation survival in wild yeasts in the bloom of icewine grapes. Food Research International, 30 (6), 435-439. https://doi.org/10.1016/S0963-9969(97)00070-7

Jarolímková, T. (2017). Laboratorní posouzení odpadního kalu z ČOV. Diplomová práce VŠCHT Praha, 37.

Liu, Y., Rousseaux, S., Tourdot-Maréchal, R., Sadoudi, M., Gougeon, R., Schmitt-Kopplin, P. and Alexandre, H. (2017). Wine microbiome: a dynamic world of microbial interactions. Critical reviews in food science and nutrition, 57 (4), 856-873. https://doi.org/10.1080/1 0408398.2014.983591

Marklein, G., Josten, M., Klanke, U., Müller, E., Horre, R., Maier, T., Wenzel, T., Kostrzewa, M., Bierbaum, G. and Hoerauf, A. (2009). Matrix-assisted laser desorption ionization-time of flight mass spectrometry for fast and reliable identification of clinical yeast isolates. Journal of Clinical Microbiology, 47 (9), 2912-2917. https://doi.org/10.1128/ JCM.00389-09

Martini, A. (1993). Origin and domestication of the wine yeast Saccharomyces cerevisiae. Journal of Wine Research, 4 (3), 165-176. https:// doi.org/10.1080/09571269308717966

Marzano, M., Fosso, B., Manzari, C., Grieco, F., Intranuovo, M., Cozzi, G., Mulè, G., Scioscia, G., Valiente, G. and Tullo, A. (2016). Complexity and dynamics of the winemaking bacterial communities in berries, musts, and wines from Apulian grape cultivars through time and 
space. PloS one, 11 (6), e0157383. https://doi.org/10.1371/journal. pone.0157383

Mortimer, R. and Polsinelli, M. (1999). On the origins of wine yeast. Research in Microbiology, 150 (3), 199-204. https://doi.org/10.1016/ S0923-2508(99)80036-9

Petruzzi, L., Capozzi, V., Berbegal, C., Corbo, M. R., Bevilacqua, A., Spano, G. and Sinigaglia, M. (2017). Microbial resources and enological significance: Opportunities and benefits. Frontiers in Microbiology, 8, 995. https://doi.org/10.3389/fmicb.2017.00995

Polsinelli, M., Romano, P., Suzzi, G. and Mortimer, R. (1996). Multiple strains of Saccharomyces cerevisiae on a single grape vine. Letters in Applied Microbiology, 23 (2), 110-114. https://doi.org/10.1111/ j.1472-765X.1996.tb00043.x

Portugal, C., Pinto, L., Ribeiro, M., Tenorio, C., Igrejas, G. and Ruiz-Larrea, F. (2015). Potential spoilage yeasts in winery environments: Characterization and proteomic analysis of Trigonopsis cantarellii. International Journal of Food Microbiology, 210, 113-120. https://doi. org/10.1016/j.ijfoodmicro.2015.06.005

Pretorius, I., Van der Westhuizen, T. and Augustyn, O. (1999). Yeast biodiversity in vineyards and wineries and its importance to the South African wine industry. A review. South African Journal of Enology and Viticulture, 20 (2),61-70. https://doi.org/10.21548/20-2-2234

Schwartz, D. C. and Cantor, C. R. (1984). Separation of yeast chromosome-sized DNAs by pulsed field gradient gel electrophoresis. Cell, 37 (1), 67-75. https://doi.org/10.1016/0092-8674(84)90301-5
Standardization, I. O. f. (2012). ISO 8586: sensory analysis: general guidelines for selection, training and monitoring of selected and expert assessors, ISO Geneva. Available from: https://www.iso.org/standard/45352.html

Török, T., Mortimer, R., Romano, P., Suzzi, G. and Polsinelli, M. (1996). Quest for wine yeasts - An old story revisited. Journal of Industrial Microbiology, 17 (3-4), 303-313. https://doi.org/10.1007/ BF01574705

Vigentini, I., De Lorenzis, G., Fabrizio, V., Valdetara, F., Faccincani, M., Panont, C. A., Picozzi, C., Imazio, S., Failla, O. and Foschino, R. (2015). The vintage effect overcomes the terroir effect: a three year survey on the wine yeast biodiversity in Franciacorta and Oltrepò Pavese, two northern Italian vine-growing areas. Microbiology, 161 (2), 362373. https://doi.org/10.1099/mic.0.000004

Zarraonaindia, I., Owens, S. M., Weisenhorn, P., West, K., Hampton-Marcell, J., Lax, S., Bokulich, N. A., Mills, D. A., Martin, G. and Taghavi, S. (2015). The soil microbiome influences grapevine-associated microbiota. mBio, 6 (2), e02527-02514. https://doi.org/10.1128/mBio.02527-14 